\title{
INFLUENCE OF THERMAL TREATMENT ON THE ELECTRONIC PROPERTIES OF ITO THIN FILMS OBTAINED BY RF CATHODIC PULVERIZATION. STUDY OF SOLAR CELLS BASED ON SILICON/ (RF SPUTTERED) ITO JUNCTIONS
}

\author{
G. CAMPET*, C. GEOFFROY, S.J. WEN, J. PORTIER \\ Laboratoire de Chimie du Solide du CNRS (LCS), Université de Bordeaux I, 351, cours de la \\ Libération, 33405 Talence Cédex, France. \\ P. KEOU, J. SALARDENNE \\ Laboratoire d'Etude des Matériaux pour la Microélectronique (LEMME), Université de Bordeaux I, \\ 351, cours de la Libération-33405 Talence Cédex, France. \\ Z.W. SUN \\ Ecole Polytechnique Fédérale de Lausanne, Institut de Physique Appliquée, PHB Ecublens, CH-1015 \\ Lausanne (Suisse) \\ (Received September 10, 1990; in final form November 6, 1990) \\ ITO (Indium Tin Oxide) thin films obtained by R.F. cathodic sputtering have been studied. The influence \\ of thermal treatment on the electronic properties of the films has been particularly investigated. Electrical \\ measurements were performed between 95 and $600 \mathrm{~K}$. Free carriers concentration in the film were \\ measured by Hall effect coefficient. Optical indices were determined by computer drawing of charts \\ allowing to simplify Manifacier method. \\ Finally study of SIS tunnel solar cells, based on $\mathrm{Si} /(\mathrm{RF}$ sputtered) ITO junctions is presented.
}

\section{INTRODUCTION}

The possible use of ITO thin films in solar energy conversion cells is supported by the excellent properties of these films:

-Good visible light transmission

-Very good mechanical resistance, particularly an excellent adherence to the substrate.

-Excellent electrical conductivity.

Although a conversion rate of $18 \%$ was obtained by M.A. Green ${ }^{1}$ with $\mathrm{Si}-\mathrm{Al}$ photovoltaic cells (Schottky type) they turn out to be very fragile due to the very small thickness $(<100 \AA)$ of the metal film. Genis et al. ${ }^{2}$ have proposed that a degenerated semi-conducting oxide film like ITO could advantageously replace a metallic thin film ${ }^{2}$. The present manuscript analyzes the influence of thermal treatment on the electrical and optical properties of RF sputtered ITO films and corresponding Si-ITO solar cells.

*To whom correspondence should be addressed. 


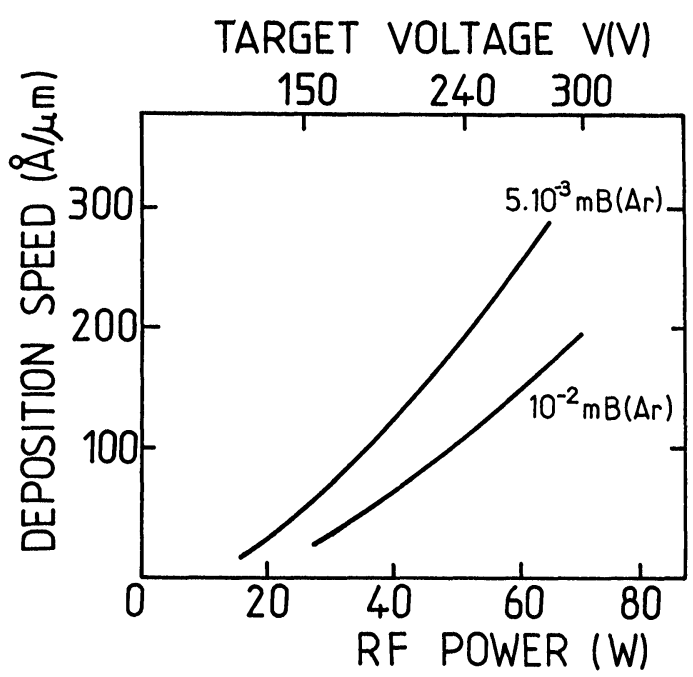

FIGURE 1 Deposition speed of ITO as a function of RF power.

\section{FILM PREPARATION}

ITO thin films were obtained by R.F. magnetron cathodic sputtering technique, using a ITO $\left(90 \% \mathrm{In}_{2} \mathrm{O}_{3}-10 \% \mathrm{SnO}_{2}\right)$ target $\left(\mathrm{P}=5 \mathrm{w}, \mathrm{p}=10^{-3} \mathrm{mb}, \mathrm{V}=240\right.$ v). As expected, the deposition rate of ITO increases with RF power (Fig. 1). The rather low deposition rate at high pressure is explained by a decrease of the mean free path of pulverized atoms.

The different types of films investigated are listed in Table I.

TABLE I

Types of films investigated.

\begin{tabular}{|c|c|c|c|c|}
\hline \multicolumn{2}{|c|}{ SAMPLE } & $\begin{array}{c}\text { Substrate } \\
\text { temp }\end{array}$ & Plasma & $\begin{array}{l}\text { Annealing process } \\
\text { - time } \\
\text { - température } \\
\text { - pressure }\end{array}$ \\
\hline \multirow{4}{*}{ A } & A1 & $300 \mathrm{~K}$ & $\mathrm{Ar}$ & no \\
\hline & $\mathrm{A} 2$ & $625 \mathrm{~K}$ & $\mathrm{Ar}$ & no \\
\hline & A3 & $300 \mathrm{~K}$ & $\mathrm{Ar}$ & $1 \mathrm{~h}, 675 \mathrm{k}, 10^{-5} \mathrm{mB}$ \\
\hline & A4 & $300 \mathrm{~K}$ & $\mathrm{Ar}$ & 1h, 675k, Air: $1 \mathrm{~B}$ \\
\hline \multirow{3}{*}{ AO } & AOI & $300 \mathrm{~K}$ & $\mathrm{Ar}+2 \% 02$ & no \\
\hline & $\mathrm{AO} 2$ & $625 \mathrm{~K}$ & $\mathrm{Ar}+2 \% 02$ & no \\
\hline & $\mathrm{AO} 3$ & $300 \mathrm{~K}$ & $\mathrm{Ar}+2 \% 02$ & $1 \mathrm{~h}, 675 \mathrm{k}, 10^{-5} \mathrm{mB}$ \\
\hline
\end{tabular}




\section{ELECTRICAL PROPERTIES OF THE FILMS}

Electrical properties have been studied under vacuum $\left(10^{-5} \mathrm{mbar}\right)$, either directly after film deposition, or after thermal treatment. Thermal treatment of the film at $675 \mathrm{~K}$ under vacuum $\left(10^{-5} \mathrm{mbar}\right)$, followed by a slow progressive cooling, gives rise to well crystallized-conductive films.

\section{1. Temperature Dependence of Resistivity}

Before annealing, thin films deposited at room temperature exhibit a decrease of the resistivity as the temperature increases. This decrease is particularly noticeable above $400 \mathrm{~K}$ (Fig. 2a). This strong variation of resistivity results from sample crystallisation (increase of carrier mobility).

A slow aging of the annealed films (when exposed to open air) is observed corresponding to a surface oxidation. Finally, annealing after aging results in a strong decrease of resistivity. Indeed, the resistivity drops from $1,15.10^{-3} \Omega \mathrm{cm}$ for non-annealed $A_{1}$ films to a value of $2 \cdot 10^{-4} \Omega \mathrm{cm}$ for annealed $A_{3}$ films (Fig. 2b). Such a low value of resistivity is also obtained for $\mathrm{A}_{2}$ films deposited on a heated substrate $(625 \mathrm{~K})$.

On the other hand annealing the films in open air $\left(\mathrm{A}_{4}\right.$ sample $)$ yields a much greater resistivity (Fig. 2b).
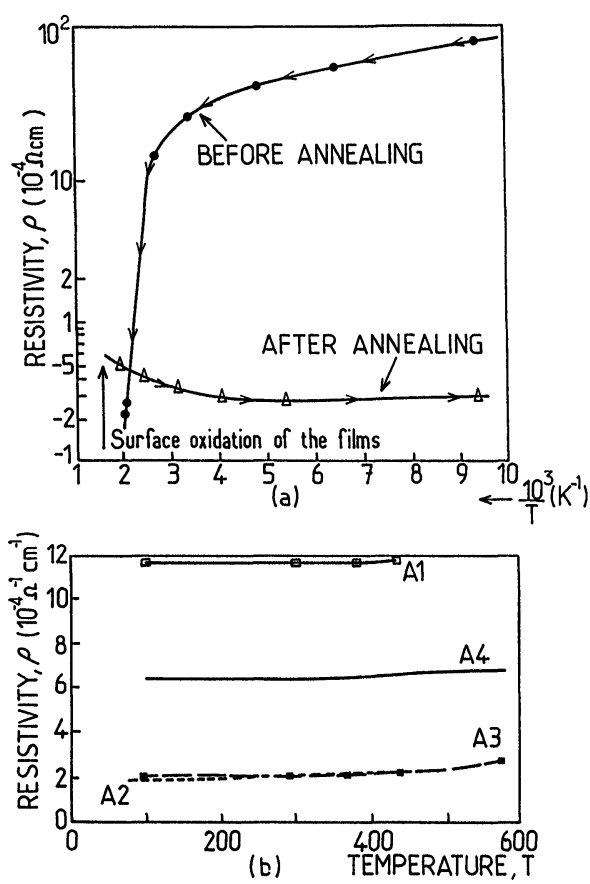

FIGURE 2 Variation of the resistivity as a function of temperature. (a): $\rho=\mathrm{f}\left(10^{3} / \mathrm{T}\right) ;(\mathrm{b})$ : $\rho=\mathrm{f}(\mathrm{T})$. 


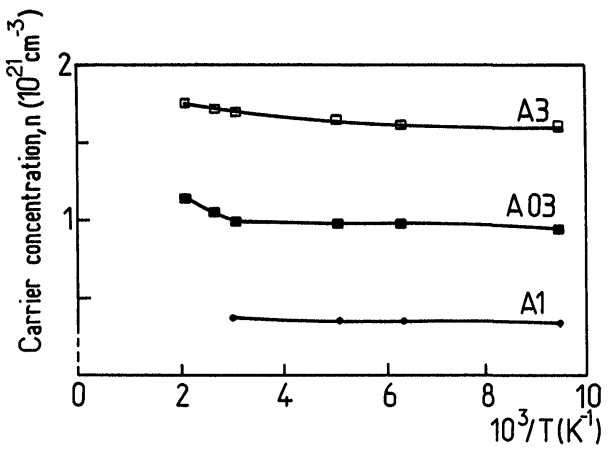

FIGURE 3 Variation of the carrier concentration as a function of temperature.

These phenomena give indirect but strong evidence that efficient $n$-type doping needs oxygen vacancies. For all films, resistivity versus temperature shows the expected metallic behaviour.

\section{2. Temperature Dependances of Free Carrier Concentration and Mobility}

Hall Effect studies give evidence of n-type conductivity. During annealing, one observes a decrease of the $R_{H}$ Hall coefficient and thus a strong increase of carriers concentration (Fig. 3). This likely corresponds to an increase of crystallinity: it would indeed lead to an increase of carriers by lowering the delocalization energy. However, as annealing occurs in vacuum, it would result in an increase of oxygen vacancies and thereby in an increase of the n-type conductivity. It is noteworthy to consider the very high doping rate obtained on type $\mathrm{AO}_{3}$ film which have been prepared under $\mathrm{Ar}+\mathrm{O}_{2}$ reacting plasma and then annealed in vacuum.

Finally, there is no significant variation of carrier concentration and mobility with temperature as one would expect for a degenerate semiconductor (Figs. 3 and 4).

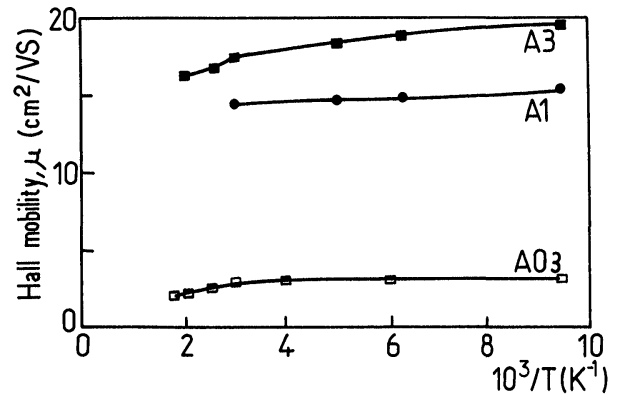

FIGURE 4 Variation of the Hall mobility as a function of temperature. 


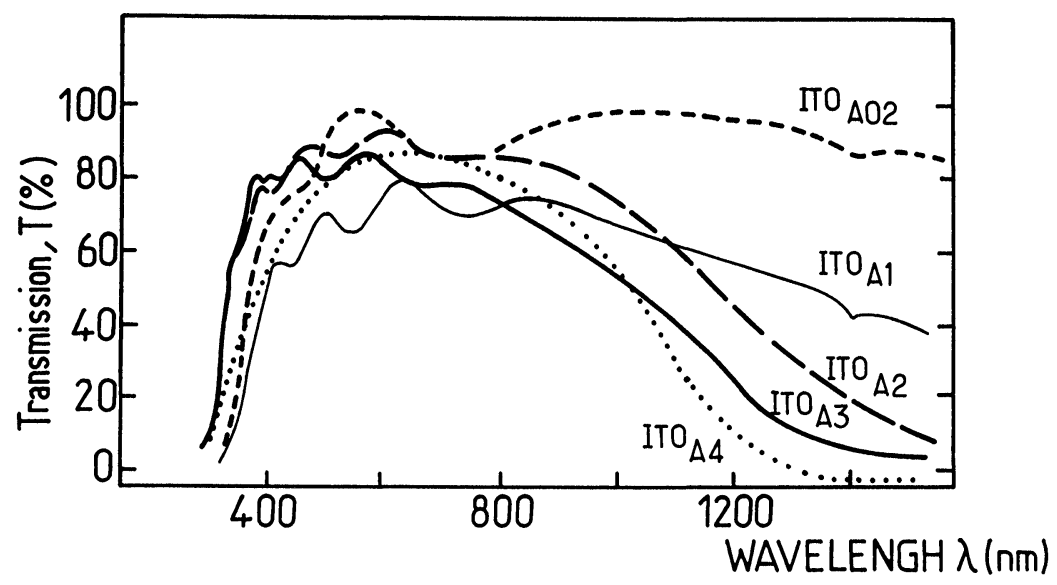

FIGURE 5 Transmission spectra of the films.

\section{OPTICAL PROPERTIES OF THE FILMS}

\section{1. Determination of the Real $\left(n^{\prime}\right)$ and Imaginary $(k)$ Part of the Refractive} Index

Optical transmission spectra $T(\lambda)$ analysis enables one to determine the variations of the real part $\left(\mathrm{n}^{\prime}\right)$ and imaginary part $(\mathrm{k})$ of the refractive index as a function of $\lambda$ in the U.V.-I.R. range (Fig. 5).

Indeed, oscillations corresponding to interferences generally occur, resulting from reflection phenomena at film-glass and/or film-air interfaces. These oscillations can be used to determine the $\mathrm{n}^{\prime}$ and $\mathrm{k}$ parameters using Manifacier's theory.

Several computer generated charts, shown in Figure 6, allow a simple determination of optical indices. Results given by this method are illustrated in Figure

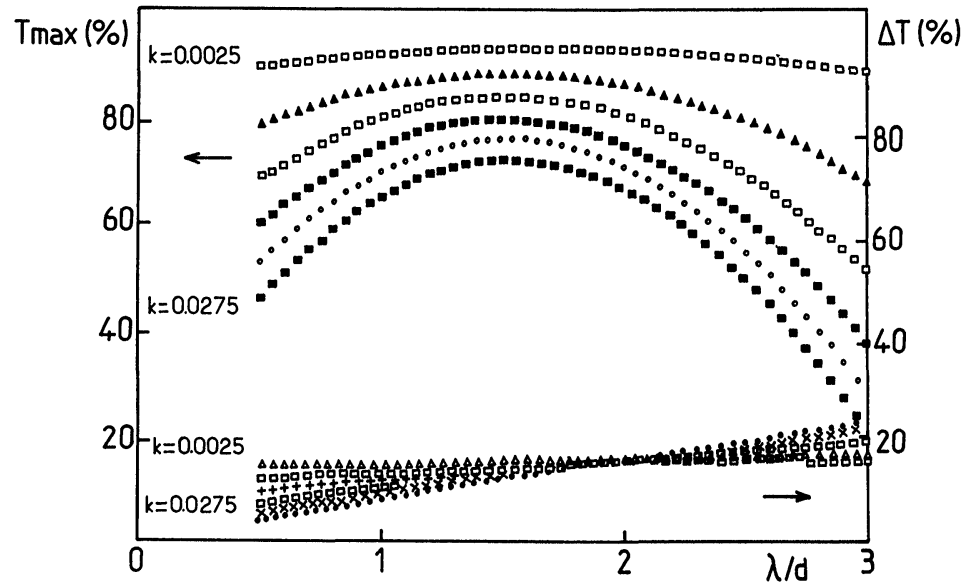

FIGURE 6 Theoretical curve $\Delta \mathrm{T}=\mathrm{f}(\lambda / \mathrm{d})$ and $\mathrm{T} \max =\mathrm{f}(\lambda / \mathrm{d})$. 


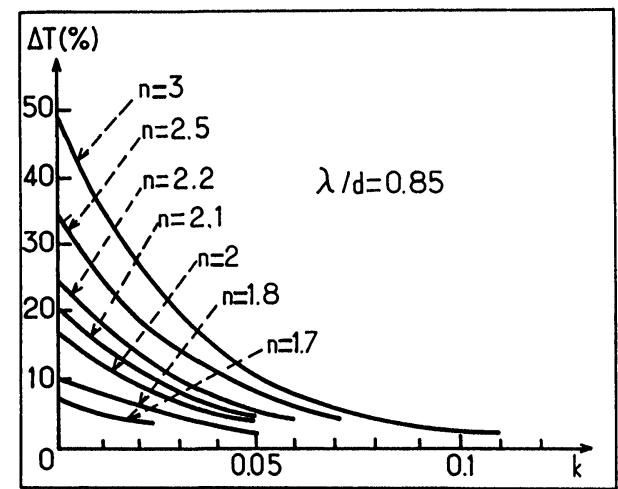

(a)

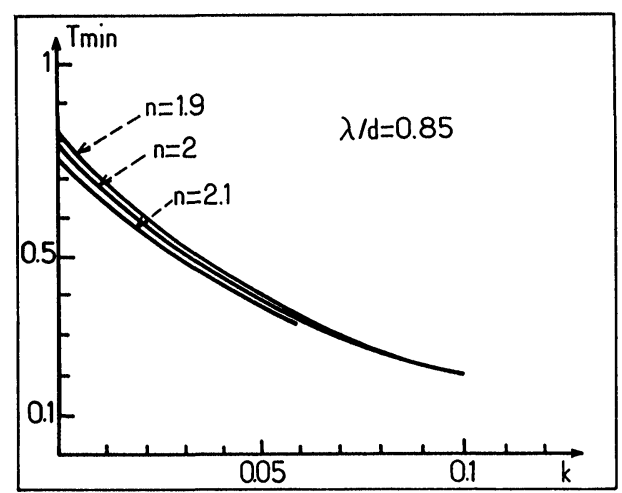

(b)

FIGURE 7 Theoretical curves $\Delta \mathrm{T}=\mathrm{f}(\mathrm{k}),(\mathrm{a})$, and $\mathrm{T}_{\min }=\mathrm{f}(\mathrm{k}),(\mathrm{b})$, for $\mathrm{n}=\mathrm{c}^{\text {te }}$ and $\lambda / \mathrm{d}=\mathrm{c}^{\text {te }}$.

7 and are supported by the calculation of transmission $T(\lambda)$ of a type $A_{1}$ layer (Fig. 8 ) using the experimental $\mathrm{n}^{\prime}$ and $\mathrm{k}$ values.

The $\mathrm{n}^{\prime}=\mathrm{f}(\lambda)$ and $\mathrm{k}=\mathrm{f}(\lambda)$ curves in the visible light range in Figure 9 clearly show that the real part $\mathrm{n}^{\prime}$ of the optical index is almost constant for all samples $(\mathrm{n}$ $\cong \sqrt{3.9}$ ). In all cases, the extinction index $\mathrm{k}$ remains much smaller than $\mathrm{n}^{\prime}$.

\section{2. Influence of Plasma Oscillations on the Optical Transmission, in the near} Infra Red Region: Determination of the Dielectric Constant $\left(\varepsilon_{\infty}\right)$ and of the Plasma Pulsation $\left(\omega_{p}\right)$

Transmission spectra obtained for type A films demonstrate a transmission in the visible larger than $8 \%$ and a strong decrease in the near infrared region (Fig. 5). We have interpreted optical phenomena in this region, with the help of classical Drude model.

According to this model, a metal can be considered as a set of $\mathrm{N}$ fixed ions and $n$ free electrons (plasma oscillations) of mass $\mathrm{m}^{*}$. The energy transfer between the 


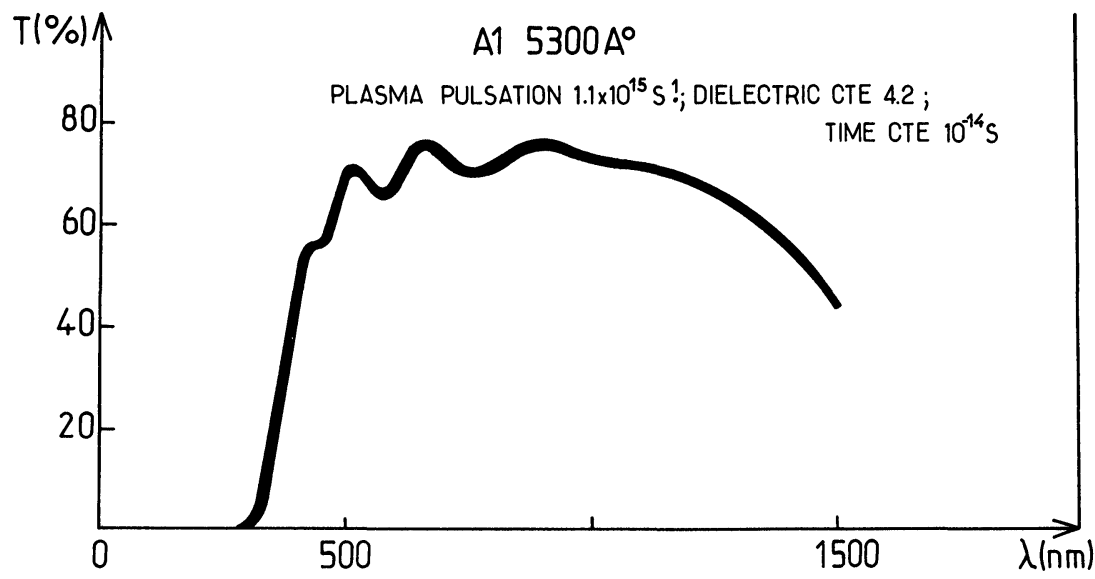

FIGURE 8 Theoretical curve $\mathrm{T}=\mathrm{f}(\lambda)$.

plasma and an electromagnetic wave can be electrically characterized by a complex dielectric constant, $\varepsilon$, such that:

$\varepsilon=1-\omega_{\mathrm{p}}^{2} /\left(\omega^{2}+\mathrm{i} \omega / \tau\right)$

where $\omega_{\mathrm{p}}$ defined by

$\omega_{\mathrm{p}}^{2}=\mathrm{ne}^{2} /\left(\varepsilon_{0} \mathrm{~m}^{*}\right)$

is the resonance pulsation of plasma and $\tau$ is the carrier relaxation time (related to the mobility according to $\mu=\mathrm{e} \tau / \mathrm{m}^{*}$ ).

One can electrically characterize the plasma by considering the total current as a displacement current: $-\mathrm{i} \omega \varepsilon_{0} \mathrm{E}$. One deduces that the dielectric constant is:

$\varepsilon=\varepsilon_{\infty}\left(1-\mathrm{ne}^{2} /\left[\varepsilon_{0} \varepsilon_{\infty} \mathrm{m}^{*}\left(\omega^{2}+\mathrm{i} \omega \mathrm{k}\right)\right]\right)=\left(\mathrm{n}^{\prime}+\mathrm{ik}\right)^{2}$

The influence of plasma oscillations on the optical transmission of ITO films is illustrated in Fig. 10.

Knowing the variation of $\mathrm{n}^{\prime}$ and $\mathrm{k}$ versus $\lambda$ (Fig. 9), one can deduce the dielectric constant $\varepsilon_{\infty}$ of the material and the pulsation $\omega_{\mathrm{p}}$ (Table II).

\section{3. Influence of Doping on Band Structure}

The first element to be considered in U.V. region is the band gap shift $(\Delta \zeta)$ given by the Burstein-Moss theory. It is given in the quasi-free electron model by:

$$
\Delta \zeta=(1 / 8) \mathrm{h}^{2}\left(\mathrm{~m}_{\mathrm{vc}}{ }^{*}\right)^{-1}(3 \mathrm{n} / \pi)^{2 / 3},
$$

where:

$\mathrm{m}_{\mathrm{vc}}=\left(1 / \mathrm{m}_{\mathrm{c}}+1 / \mathrm{m}_{\mathrm{v}}\right)^{-1}$ 

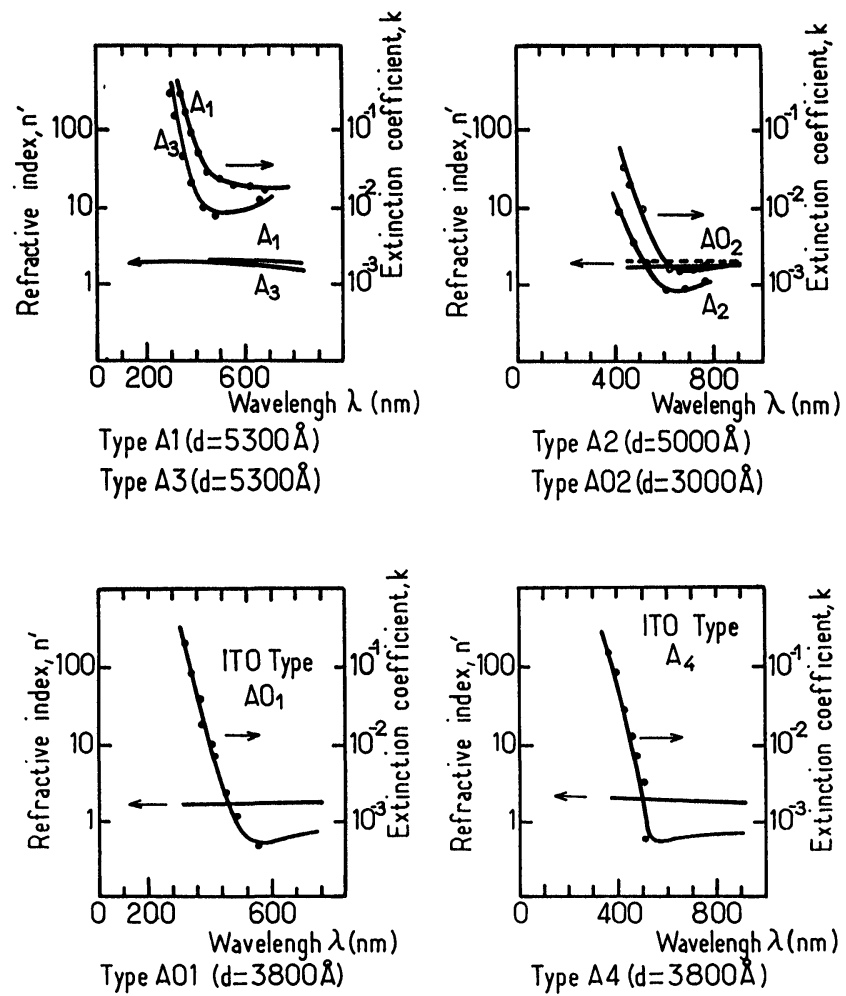

Type $A 4(d=3800 \AA)$

FIGURE 9 Wavelength dependence of the optical constants $n^{\prime}$ and $k$.

$m_{c}$ and $m_{v}$ are respectively the reduced effective mass in conduction and valence bands.

The observed values for $\Delta \zeta$ are smaller than the one predicted by the BursteinMoss effect and corresponds to $1 / \mathrm{m}_{\mathrm{vc}}<1 / \mathrm{m}_{\mathrm{c}}$. The value of $\mathrm{m}_{\mathrm{vc}}$ obtained $(\simeq 0,6$ $\mathrm{m}_{0}$ ) leads to a negative value of $\mathrm{m}_{\mathrm{v}}$. This anomaly can be avoided ${ }^{3}$ by taking into

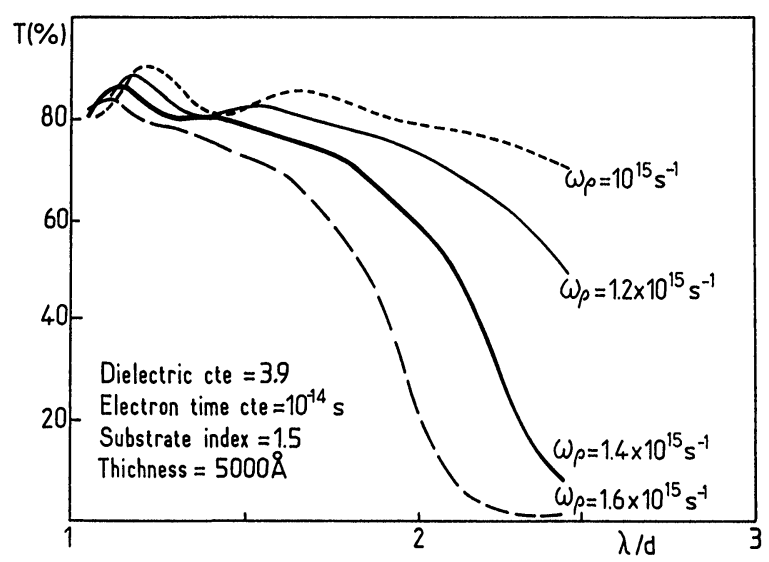

FIGURE 10 Influence of plasma oscillations on the optical properties of ITO films (theoretical curve). 
TABLE II

Dielectric constant $\left(\varepsilon_{\infty}\right)$ and pulsation (wp) of several films.

\begin{tabular}{|c|c|c|c|c|}
\hline Film type & $\mathrm{A} 1$ & $\mathrm{~A} 2$ & $\mathrm{~A} 3$ & $\mathrm{AO} 1$ \\
\hline$\varepsilon_{x}$ & 4,2 & 3,7 & 3,9 & 4,1 \\
$\omega_{\mathrm{p}}\left(\mathrm{s}^{-1}\right)$ & $9,4.10^{14}$ & $1,2.10^{15}$ & $1,4.10^{15}$ & $6,8.10^{14}$ \\
\hline
\end{tabular}

account the other effects which are responsible for a decrease of the absorption threshold. At first, what we may call electron-electron interactions increase with free carrier concentration. The resulting screening of the periodic potential lattice induces a significant decrease of the band gap width. Moreover, one must take into account electron-impurity interactions.

\section{STUDY OF SIS (SEMICONDUCTOR-INSULATOR- SEMICONDUCTOR) TUNNEL SOLAR CELLS, BASED ON $\mathrm{Si} /$ (RF SPUTTERED) ITO JUNCTIONS}

Because of their transparency, electrical conductivity and electron affinity ${ }^{4}$, A2type ITO films were deposited onto $\mathrm{p}-\mathrm{Si}((100)$ face), to fabricate SIS (Semiconductor/Insulator/Semiconductor: $\mathrm{p}$-Si/SiO $/$ ITO) tunnel-solar-cells (Fig. 11).

The ohmic back contact is assured by silver paste on $\mathrm{p}$-Si; indeed, silver forms the ohmic contact on p-Si because of the alloying effects between $\mathrm{Ag}$ and $\mathrm{SiOx}^{5}$.

Different etching processes of silicon surfaces have been used in order to minimize the influence of the interface states ${ }^{6}$. Thus, there is no Fermi level pinning effects observed, as shown in Table III.

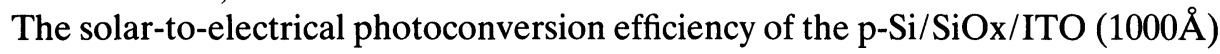
cell is small $(\eta<1 \%)$ because of the existence of a thick insulating interfacial layer of $\mathrm{SiOx}^{6}(\mathrm{~d}>20 \AA)$ which is inherent to the experimental conditions (Fig. 12).

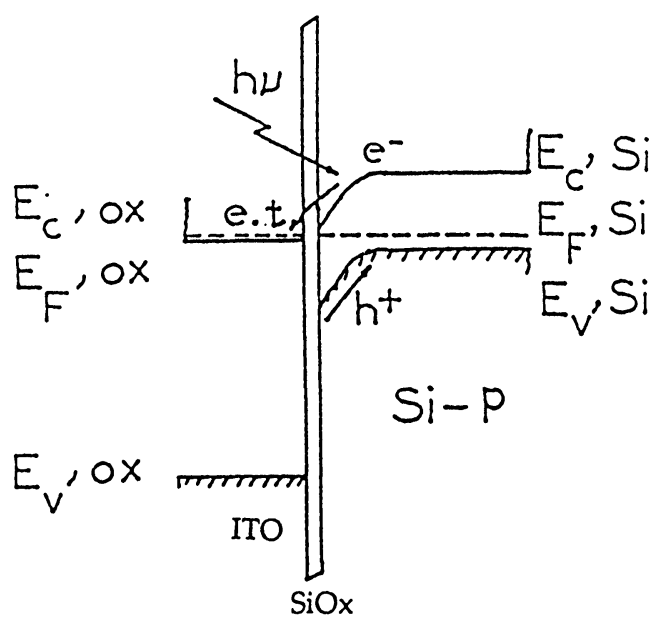

FIGURE 11 Energy band diagram of SIS solar cells. 
TABLE III

The Schottky-barrier heights $\left(\phi_{\mathrm{B}}\right)$ of the solar cells.

\begin{tabular}{|c|c|c|}
\hline Cell & $\begin{array}{c}\phi_{\mathrm{B}} \text { measured by } \\
\text { transient photocurrent }\end{array}$ & $\begin{array}{c}\phi_{\mathrm{B}} \text { calculated from } \\
\text { the difference of } \mathrm{E}_{\mathrm{F}}\end{array}$ \\
\hline $\mathrm{Si}-\mathrm{p} / \mathrm{SiO} \chi / \mathrm{ITO}$ & $0.90 \mathrm{eV}$ & $0.93 \mathrm{eV}$ \\
\hline
\end{tabular}

\section{CONCLUSION}

Our work allowed us to optimize the preparation conditions of ITO thin films and obtain resistivities as low as $2.10^{-4} \Omega$-cm together with a transmission in the visible greater than $80 \%$ and with a strong reflectivity in the IR region.

Such an efficient n-type doping was reported elsewhere ${ }^{7}$; however, we have shown that oxygen vacancies are required. Indeed, the oxygen vacancies introduce donor centers which can be likened to electrons in cationic 5s orbitals; these donor energy states are located in the vicinity of the conduction band edge so that for high oxygen vacancy concentration $\left(\geq 10^{20}-10^{21} \mathrm{~cm}^{-3}\right)$ the Fermi energy lies well above $(\sim \Delta \zeta \mathrm{eV})$ the conduction band edge. We attempted to theoretically account for the electrical and optical properties of the films. We observed that preparation conditions strongly affect the mobility. In particular one may notice that films prepared in oxidizing atmosphere, then annealed in vacuum, yield a weak mobility. Indeed ITO films prepared in oxidizing $\mathrm{Ar}-\mathrm{O}_{2}$ atmosphere would have a lower value of the oxygen vacancy concentration, and thereby a lower value of the Fermi

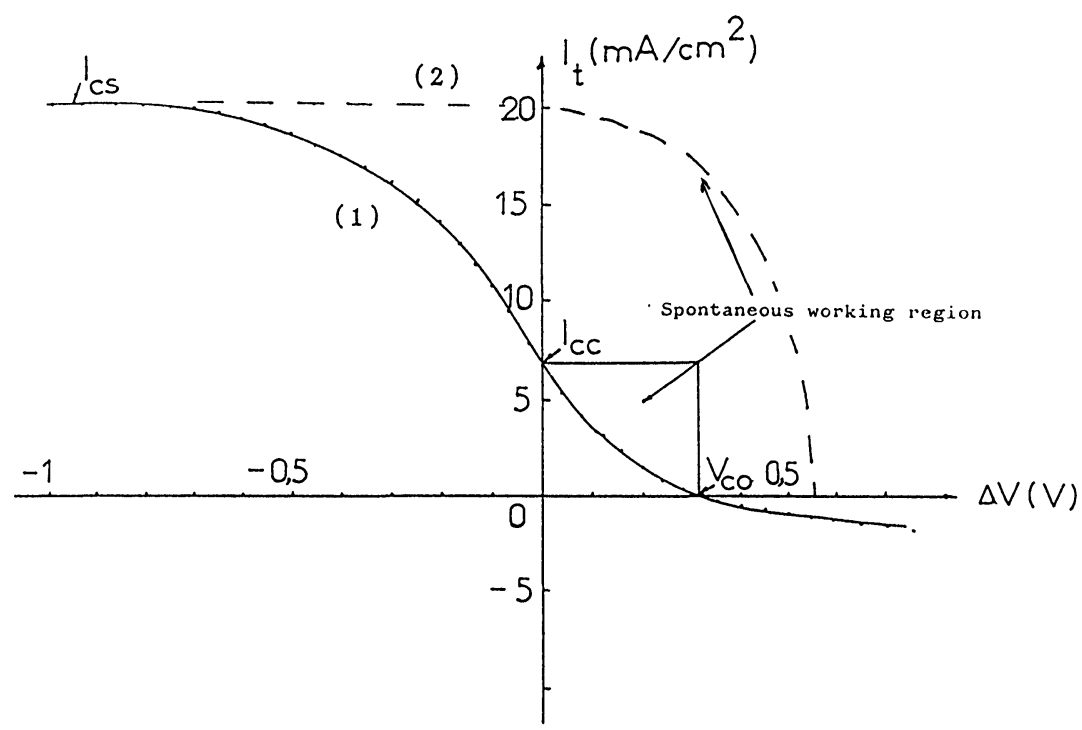

FIGURE 12 I-V Characteristics of the Si-p/SiOx/ITO cells:

(1) Experimental curve

(2) Expected curve if $d_{\text {SiOx }}<20 \AA$. 
energy, than those deduced for films prepared in Ar atmosphere. Consequently the Fermi level would lie below the mobility edge for the former films only.

\section{ACKNOWLEDGEMENT}

The authors wish to thank Dr. R. Castellano, editor, Active and Passive Electronic Components, for very helpful discussions.

\section{REFERENCES}

1. M.A. Green et al., Proc. 14th Photov. Spec. Conf. San Diego, CA IEEE, New York 684 (1980).

2. A.P. Genis et al., Proc. 9th Intern. Conf. on electron and ion beam Science and Technology, Electrochem. Soc., Princeton, NJ (1980).

3. R. Aitchison Austr. J. Appl. Sci. 5, 10 (1954).

4. G. Campet, C. Geoffroy, J.P. Manaud, J. Portier, Z.W. Sun, J. Salardenne and P. Keou, Mat. Sc. and Engineering (accepted 1990).

5. T.E. Sullivan, R.B. Childs, J.M. Ruths, S.J. Fonash in the "Physics of $\mathrm{SiO}_{2}$ and its interfaces" edited by S.T. Pantelides, Pergamon Press, New York, 454 (1978).

6. G. Campet, Z.W. Sun and P. Keou. J of Act. and Pass. El. Comp. 14, 47 (1990).

7. K.L. Chopra, S. Major and D.K. Pandya, Thin Solid Films, 102, 1 (1983). 

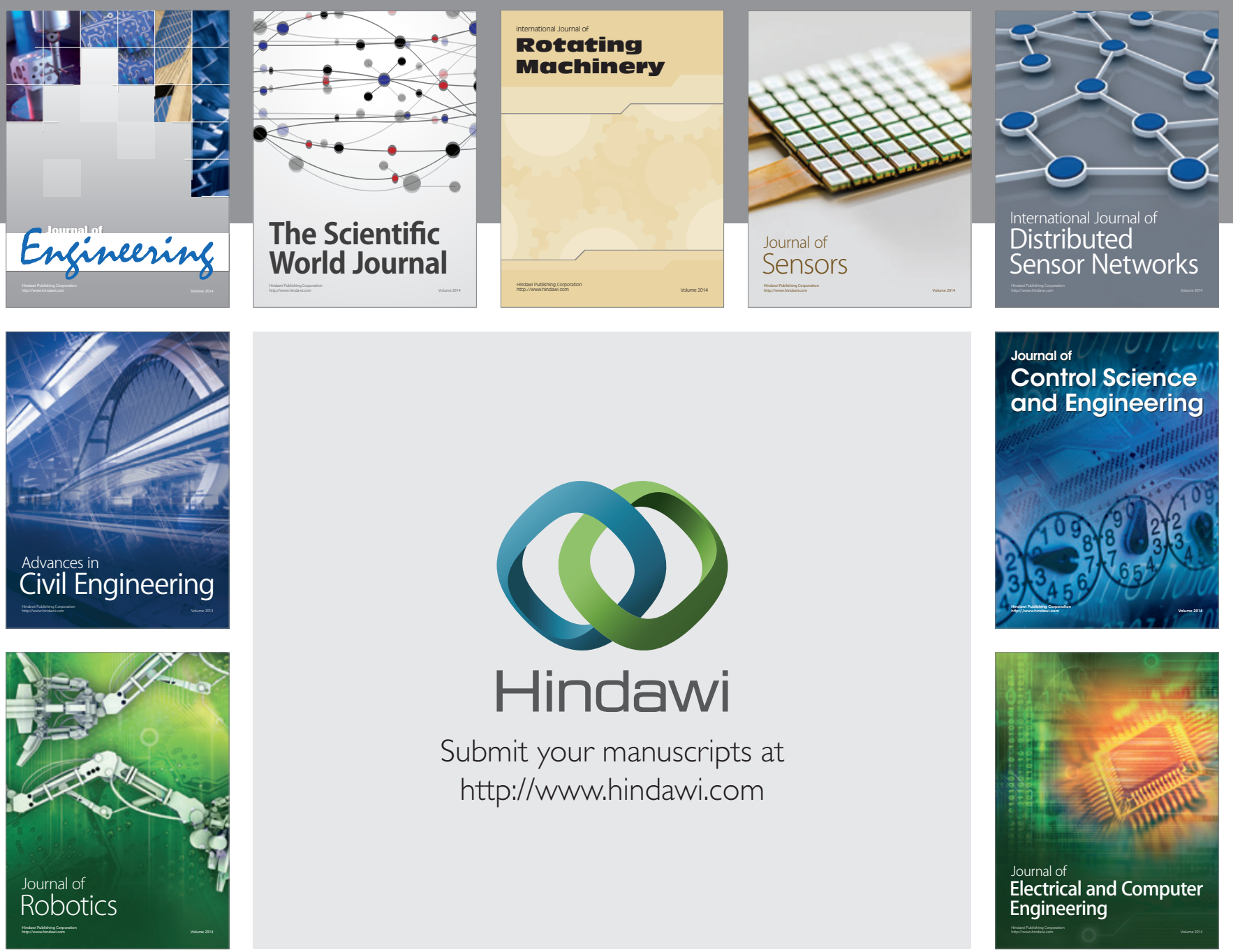

Submit your manuscripts at

http://www.hindawi.com
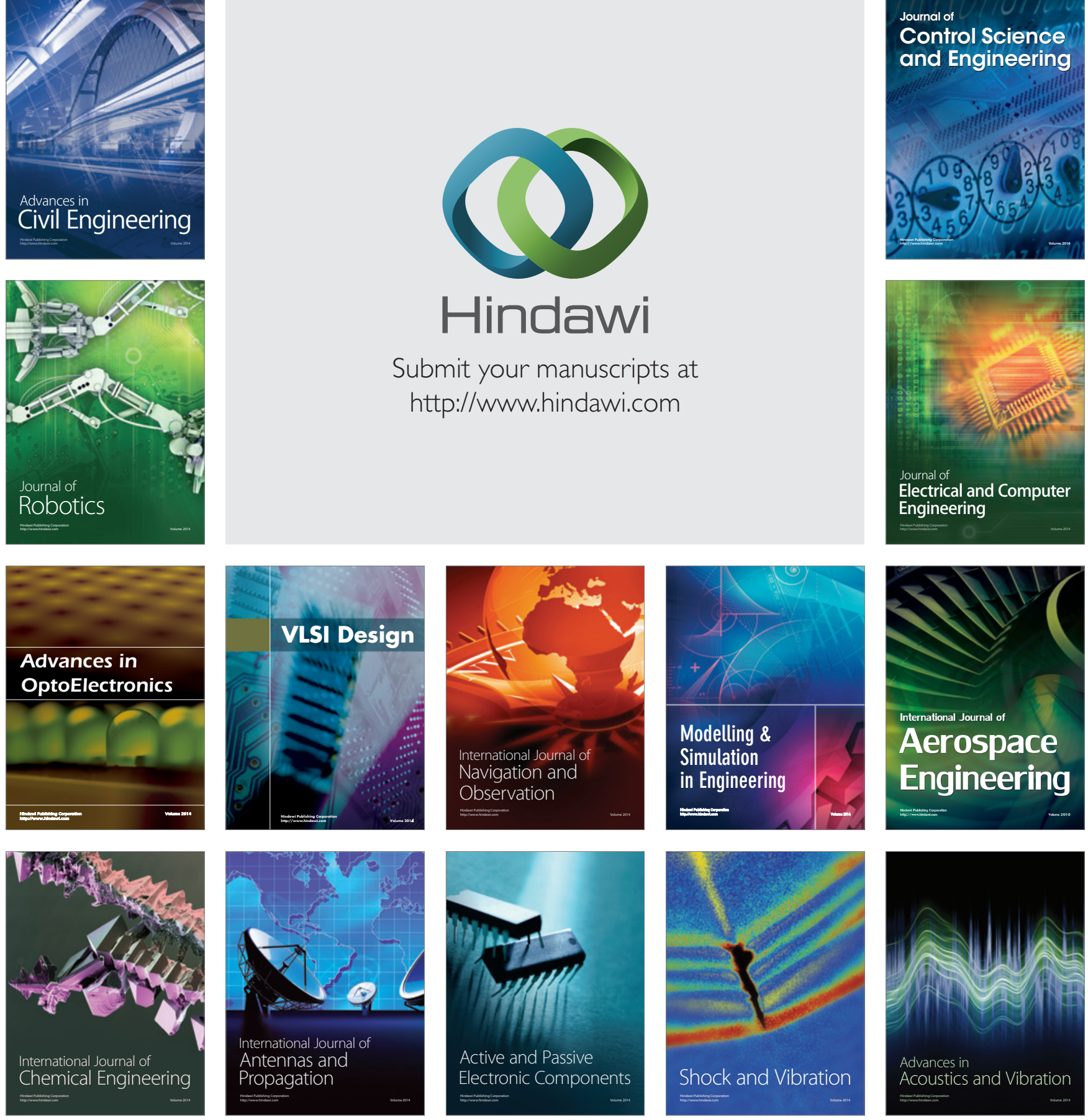